\title{
SCANNING ELECTRON MICROSCOPY AND VOLTAMMETRY OF PREFERENTIALLY ORIENTED POLYCRYSTAI.IINE PLATINUM SURFACES
}

\author{
R.M. CERVINO *, A.J. ARVIA ${ }^{* *}$ and W. VIELSTICH \\ Institute of Physical Chemistry, University of Bonn, D-5300 Bonn, Fed. Rep. of Germany
}

Received 7 November 1984; accepted for publication 10 December 1984

\begin{abstract}
Scanning electron micrographs are taken for a polycrystalline platinum wire before and after the application of a repetitive potential scan at more than $10,000 \mathrm{~V} / \mathrm{s}$. The change of the surface structure observed is related to a specific hydrogen adatom voltammogram usually obtained for single crystal surfaces.
\end{abstract}

\section{Introduction}

Platinum single crystal surfaces can be characterized by structure-sensitive methods such as LEED [1] or RHEED [2] or more conveniently by using underpotential deposition of hydrogen or copper [3]. This characterization is of special importance in order to assess the structure sensitivity of electrocatalytic processes as, e.g., oxygen reduction [1] or formic acid oxidation [4].

Recently, Cervino, Triaca and Arvia [5] have made the observation that the hydrogen adatom voltammetric fingerprints of platinum single crystal surfaces can be obtained via an electrochemical preparation of polycrystalline platinum material. The treatment consists in the application of a very fast potential scan to the polycrystalline material in aqueous electrolytes. In a typical approach scan rates between 1000 and $15,000 \mathrm{~V} / \mathrm{s}$ and $1 \mathrm{M} \mathrm{H}_{2} \mathrm{SO}_{4}$ solution are used. Applying a fast potential scan in the range of 400 to $1600 \mathrm{mV}$ (NHE) results in an electrode surface which according to the voltammogram in the same electrolyte at conventional sweep rates, e.g. $0.1 \mathrm{~V} / \mathrm{s}$ exhibits the characteristics of that described by Hubbard et al. [6] for $\mathrm{Pt}(111)$ single crystal electrodes after it has been cycled a few limes at $10 \mathrm{mV} / \mathrm{s}$ covering partially the $O$ adatom electrosorption potential range.

* Guest scientist from La Plata, Argentina.

** INIFTA, La Plata, Argentina.

0039-6028/85/\$03.30 (1) Elsevier Science Publishers B.V.

(North-Holland Physics Publishing Division) 
The extension of the cathodic potential limit into the hydrogen adsorption region leads to the formation of a surface with a voltammetric behaviour very similar to that of a $\mathrm{Pt}(100)$ single crystal [6]. While at scan rates between 1 and $100 \mathrm{~V} / \mathrm{s}$ a typical increase of the platinum surface is observed, this is not the case in the development of crystallographic orientations on polycrystalline platinum as described above.

In principle, the form of the periodic perturbation signal in the relatively large frequency range $(0.5<f<5 \mathrm{kHz})$ seems to be of minor importance. The application of a square wave potential sequence leads to results [7] similar to the use of a triangular potential sweep.

The new surface structure formed via the electrochemical procedure is sufficiently stable to participate in electrooxidation reactions without noticeable reconstruction at potentials lower than $0.9 \mathrm{~V}$ and sweep rates no greater than $0.5 \mathrm{~V} / \mathrm{s}$, especially in the case of the $\mathrm{Pt}(100)$ preferentially oriented surface. It can also stay unaltered in contact either with air or with distilled water for hours.

An easy test of the similarities between the preferentially oriented platinum electrodes prepared by potential scan application and the corresponding (111) and $(100)$ single crystal platinum surfaces is the examination of the electrocatalytic properties. First measurements [8] of the voltammograms for the electrooxidation of adsorbed residues from $\mathrm{CO}$, reduced $\mathrm{CO}_{2}, \mathrm{HCOOH}, \mathrm{CH}_{3} \mathrm{OH}$ and ethylene glycol are very similar to those given in the literature for the corresponding $\mathrm{Pt}$ single crystal electrodes [4].

In the investigation of the new effect the study of the surface by physical methods such as electron microscopy and LEED or RHEED is still missing. An obvious complication in applying these methods is the fact that only small areas of single crystal surfaces are to be exected on top of the polycrystalline material, with different angles of orientation.

\section{Scanning electron micrographs of preferentially oriented platinum surfaces}

Polycrystalline platinum wires (Degussa 99,97) of $0.8 \mathrm{~mm}$ diameter and 1 $\mathrm{cm}$ length were subjected to a $10,000 \mathrm{~V} / \mathrm{s}$ potential scan in $1 \mathrm{M} \mathrm{H}_{2} \mathrm{SO}_{4}$ between 0.42 and $1.08 \mathrm{~V} \mathrm{NHE}$ for $12 \mathrm{~h}$. After washing in distilled water, the SEM micrograph (fig. 1a) was obtained with a Scanning Electron Microscope Cambridge S4.

As it was to be expected, a rearrangement of the surface has taken place producing net planes with different angles of orientation with respect to the substrate plane. The mosaic structure of fig. 1 which includes steps is obviously different from the surface morphology of the untreated sample (fig. 2a).

A voltammogram run immediately after the preparation of the platinum surface shown in fig. 1a, by applying a symmetrical triangular potential scan of 

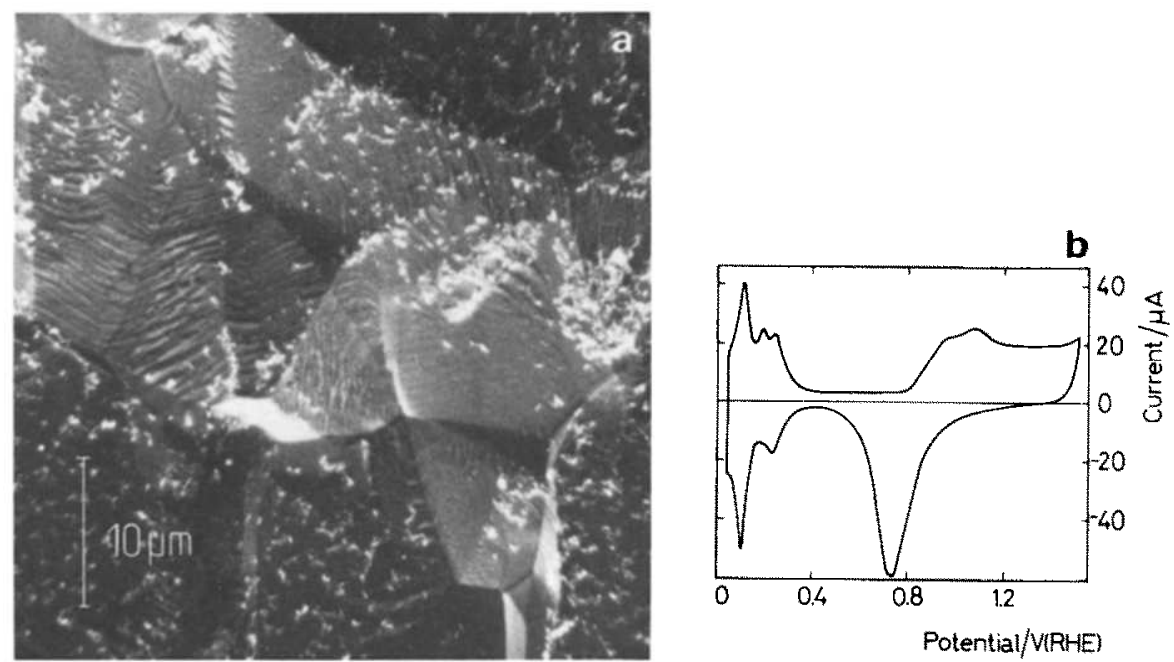

Fig. 1. (a) Scanning electron micrograph (magnification 2300) of a polycrystalline platinum wire after a repetitive potential sean at $10,000 \mathrm{~V} / \mathrm{s}$ during $12 \mathrm{~h}$ between 420 and $1080 \mathrm{mV} \mathrm{RHE}$ in $1.0 \mathrm{M}$ $\mathrm{H}_{2} \mathrm{SO}_{4}$ and (b) the corresponding cyclic voltammogram in $1.0 \mathrm{M} \mathrm{H}_{2} \mathrm{SO}_{4}, 100 \mathrm{mV} / \mathrm{s}$.

$100 \mathrm{mV} / \mathrm{s}$ in the $40-1500 \mathrm{mV}$ range (fig. $1 \mathrm{~b}$ ) shows a close resemblance with the characteristics of a $\mathrm{Pt}(111)$ single crystal surface [6]. Fig. 2b shows for comparison the voltammogram of the starting polycrystalline platinum electrode under the same conditions as in fig. $1 \mathrm{~b}$.
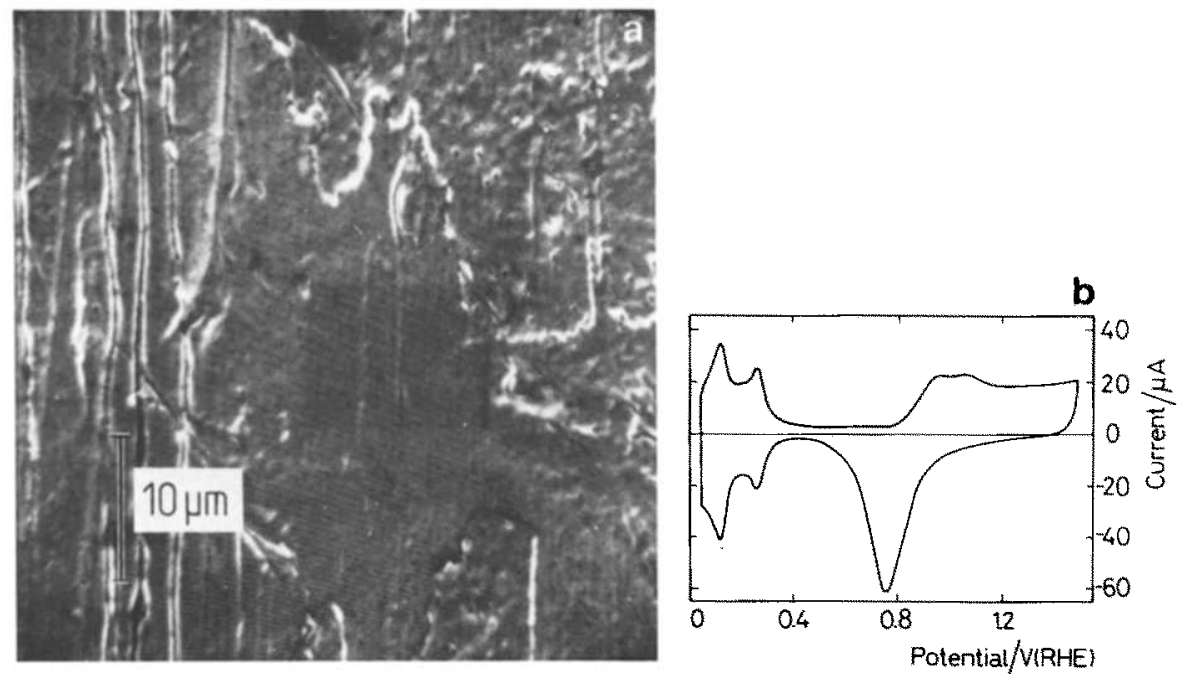

Fig. 2. (a) Scanning electron micrograph (magnification 2300) of a polyerystalline platinum wire and (b) the corresponding cyclic voltammogram in $1.0 \mathrm{M} \mathrm{H}_{2} \mathrm{SO}_{4}, 100 \mathrm{mV} / \mathrm{s}$. 

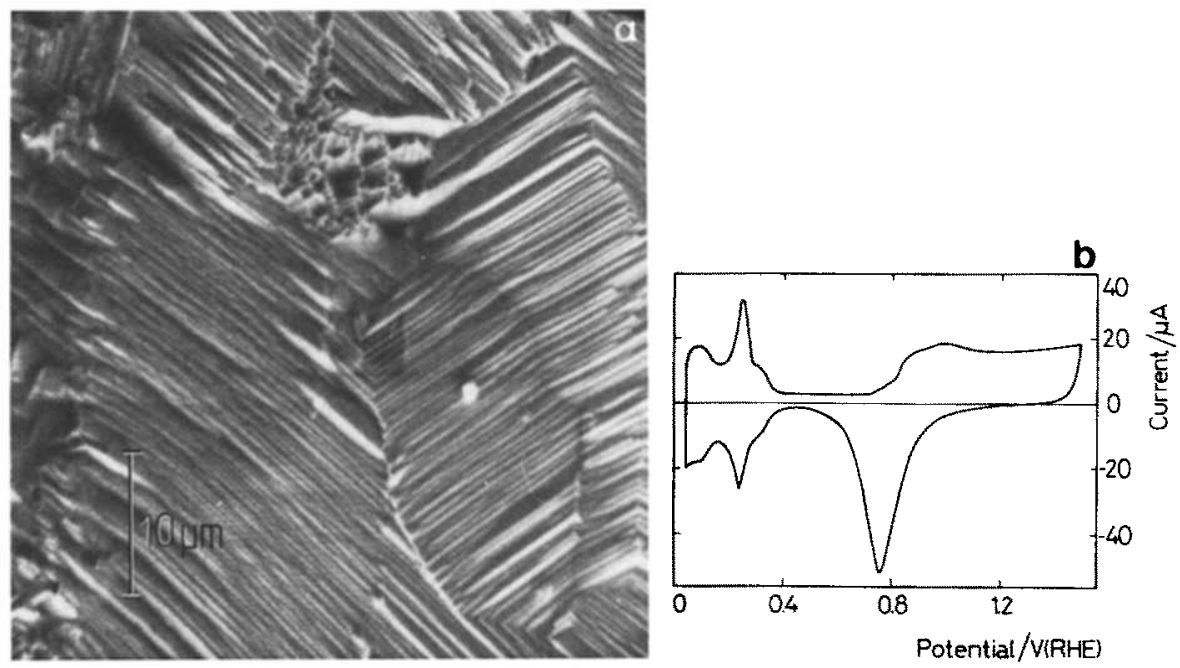

Fig. 3. (a) Scanning electron micrograph (magnification 2200) of a polycrystalline platinum wire after a repetitive scan at $14,000 \mathrm{~V} / \mathrm{s}$ during $12 \mathrm{~h}$ between 23 and $1320 \mathrm{mV}$ RHE in $1.0 \mathrm{M} \mathrm{H}_{2} \mathrm{SO}_{4}$ and (b) the corresponding cyclic voltammogram in $1.0 \mathrm{M} \mathrm{H}_{2} \mathrm{SO}_{4}, 100 \mathrm{mV} / \mathrm{s}$.

Another micrograph was obtained for a polycrystalline $\mathrm{Pt}$ wire after the application of a $14,000 \mathrm{~V} / \mathrm{s}$ potential scan between 23 and $1320 \mathrm{mV}$ for $12 \mathrm{~h}$ (fig, 3a). The surface morphology is again very different from both, the original sample and that shown in fig. 1a. The surface appears to be smoother than after the first treatment and exhibits a parallel-channel-like structure. In this case, the voltammogram run at $100 \mathrm{mV} / \mathrm{s}$ between 40 and $1500 \mathrm{mV}$ (fig. $3 \mathrm{~b}$ ) resembles closely that described in the literature for the $\mathrm{Pt}(100)$ single crystal surface [1,2].

The electrochemical surface modification is obviously connected with the early stage of an $\mathrm{Pt}-\mathrm{OH}$ or $\mathrm{Pt}-\mathrm{O}$ formation. However, in order to suggest a mechanism for the effect observed more experimental information is still necessary.

\section{Preparation of larger preferentially oriented platinum surfaces $\left(>0.5 \mathrm{~cm}^{2}\right)$}

For the surface modification of polycrystalline platinum electrodes of a geometric area greater than $0.1 \mathrm{~cm}^{2}$ a high power potentiostat $(20 \mathrm{~A}, 12 \mathrm{~V})$ with a good frequency response up to $20 \mathrm{kHz}$ is advantageous. In this case, in order to avoid oscillations, the standard circuit $[9,10]$ has been modified by the addition of a filter for frequencies $>100 \mathrm{kHz}$.

With this high power potentiostat the preferred orientation of polycrystalline platinum sheets of $5 \times 10 \mathrm{~mm}^{2}$ could be accomplished. The corresponding 


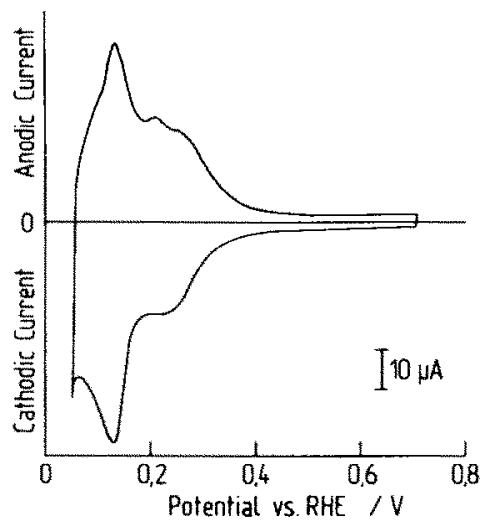

Fig. 4. Cyclic voltammogram $(100 \mathrm{mV} / \mathrm{s})$ in $1.0 \mathrm{M} \mathrm{H}_{2} \mathrm{SO}_{4}$ for a polycrystalline platinum sheet $\left(4 \times 8 \mathrm{~mm}^{2}\right)$ after a repetitive potential scan at $10,000 \mathrm{~V} / \mathrm{s}$ between 320 and $1080 \mathrm{mV}$ RHE.

voltammetric response in the $H$ adatom potential region is similar to that obtained with wire electrodes of smaller area.

Fig. 4 shows the voltammogram of a polycrystalline Pt sheet after applica-

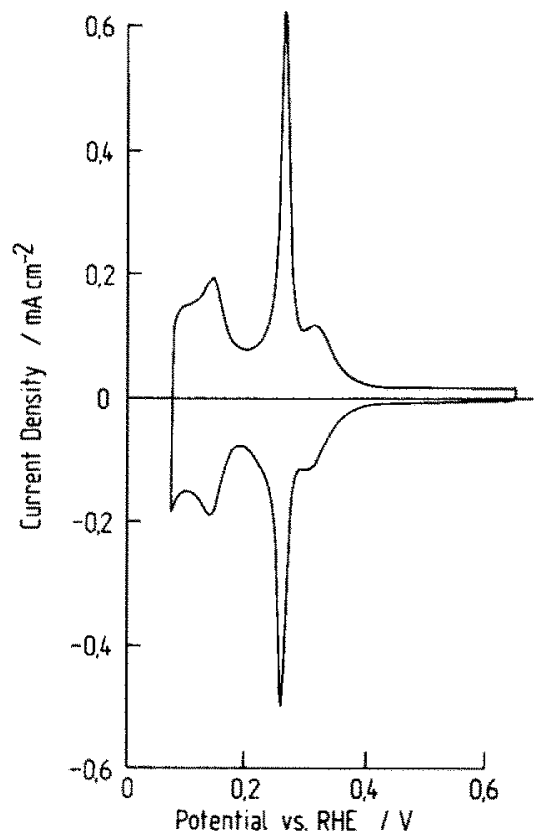

Fig. 5. Cyclic voltammogram of polycrystalline platinum as in fig. 4 after a repetitive potential scan at $13,000 \mathrm{~V} / \mathrm{s}$ between 40 and $1400 \mathrm{mV}$ RHE. 
tion of a very fast potential scan covering the double layer region and the lower part of the oxygen adatom electroadsorption region. Comparing the pronounced peak structure in the hydrogen region with the results of single crystal experiments (see, e.g. refs. $[3,6]$ ), one comes to the conclusion that oriented areas have been formed with a predominance of sites for hydrogen adsorption similar to those existing on (cycled) (111) surfaces.

The same experiment as in fig. 4 but with inclusion of the hydrogen adatom potential region in the fast potential scan treatment, results in the voltammogram of fig. 5. According to the peak structure obtained one has developed surface layers with a predominance of sites for hydrogen adsorption similar to those existing on (cycled) (100) surfaces [3,6]. After dissolving the upper layers in aqua regia at boiling temperature (for 1-3 min) the voltammograms of the remaining surface structure prove that several layers must be modified by the described electrochemical perturbation method.

Finally, it should be noticed that the preferentially oriented surfaces of polycrystalline platinum induced by fast potential perturbations correspond to structural changes in the surface which are comparable to those achieved from thermal and chemical pretreatments, applied to either single or polycrystalline platinum and followed by voltammetry. This matter will be discussed in a future publication.

\section{Acknowledgements}

The authors acknowledge the help of B. Fassbender in developing a high power potentiostat and the assistance of Dr. A Maas to obtain the SEM patterns. R.C. thanks DAAD the fellowship granted through the University of Mainz - University of La Plata Cooperation Agreement.

\section{References}

[1] P.N. Ross, J. Electrochem. Soc. 126 (1979) 78.

[2] K. Yamamoto, D.M. Kolb, R. Kötz and G. Lehmpfuhl, J. Electroanal. Chem. 96 (1979) 233.

[3] C.L. Scortichini and Ch.N. Reilley, J. Electroanal. Chem. 139 (1982) 233.

[4] C. Lamy, J.M. Leger, J. Clavilier and R. Parsons, J. Electroanal. Chem. 150 (1983) 71.

[5] R.M. Cervino, W.E. Triaca and A.J. Arvia, J. Electrochem. Soc. 132 (1985) 266.

[6] A.T. Hubbard, R.M. Ishikawa and J. Katekaru, J. Electroanal. Chem. 86 (1978) 289.

[7] J.C. Canullo, W.E. Triaca and A.J. Arvia, J. Electroanal. Chem., in press.

[8] E.P.M. Leiva, E. Santos, R.M. Cervino, M.C. Giordano and A.J. Arvia, Electrochim. Acta, in press.

[9] W. Vielstich and H. Gerischer, Z. Physik. Chem. (NF) 3 (1955) 10.

[10] F.G.Will and C.A. Knorr, Ber. Bunsenges. Physik. Chem. 64 (1960) 260. 